DOSSIÊ TEMÁTICO: Formação Docente, Práticas Pedagógicas e Relações Raciais e de Gênero

do1 https://doi.org/10.22481/praxisedu.v16i39.6363

\title{
NARRATIVAS MIDIÁTICAS SOBRE A SEXUALIDADE: EDUCAÇÃO, DIFERENÇAS E PROBLEMÁTICAS À FORMAÇÃO DOCENTE
}

\author{
MEDIA NARRATIVES ON SEXUALITY: EDUCATION, DIFFERENCES AND \\ PROBLEMS WITH TEACHER TRAINING
}

\begin{abstract}
NARRATIVAS MEDIÁTICAS SOBRE LA SEXUALIDAD: EDUCACIÓN, DIFERENCIAS Y PROBLEMÁTICAS A LA FORMACIÓN DOCENTE
\end{abstract}

\author{
Delton Aparecido Felipe \\ Universidade Estadual de Maringá - Brasil
}

Samilo Takara

Universidade Federal de Rondônia - Brasil

\begin{abstract}
Resumo: A sexualidade humana é um dos elementos que nos permite pensar a formação das identidades dos sujeitos e, considerando que a escola é um espaço em que estão presentes múltiplos indivíduos, com suas construções identitárias, este texto tem a seguinte questão norteadora: Quais as contribuições das narrativas midiáticas para problematizar as sexualidades no espaço escolar? Para tanto, apoiamos nossas reflexões teóricas a partir dos Estudos Culturais, por entende-los como um campo que analisa a mídia como um terreno de disputa, no qual os grupos sociais lutam pelo domínio. No decorrer do texto, defendemos a ideia de que, ao levarmos as narrativas midiáticas acerca das diferentes sexualidades para o espaço escolar, contribuímos para uma ação docente que valorize os diferentes alunos e alunas que habitam a sala de aula e, ainda, buscamos demonstrar isso por meio da análise de alguns personagens da série da Netflix, intitulada Sex Educacion (2019). Concluímos, assim, que a ação pedagógica com as mídias para discutir sexualidade, possibilita o processo de visibilidade dessas múltiplas formas de ser e estar no mundo, além de colaborar com uma formação de professores e professoras comprometidas com uma política cultural implica contemplem todos os alunos e as alunas em sala em suas dimensões sociais e sexuais.
\end{abstract}

Palavras-chave: Formação docente; Narrativa midiáticas; Sexualidades.

Abstract: Human sexuality is one of the elements that allows us to think about the formation of the identities of the subjects and, considering that the school is a space in which multiple individuals are present, with their identity constructs, this text has the following guiding question: What are the contributions of media narratives to the problematization of sexualities in schools? For this, we support our theoretical reflections from the Cultural Studies, by understanding them as a field that analyzes the media as a ground of dispute, in which social groups struggle for the domain. In the course of the text, we advocate the idea that, by taking the media narratives about the different sexualities into the school space, We contribute to a teaching action that values the different students 
that inhabit the classroom and, still, we seek to demonstrate this by analyzing some characters from the series Netflix, titled Sex Educacion (2019).We conclude, thus, that the pedagogical action with the media to discuss sexuality, enables the process of visibility of these multiple forms of being and being in the world, besides collaborating with the formation of teachers and teachers committed to a cultural policy implies that they contemplate all students and students in class in their social and sexual dimensions

Keywords: Teacher training; Media narrative; Sexualities.

Resumen: La sexualidad humana es uno de los elementos que nos permite pensar laformación de las identidades de lossujetos y, considerando que laescuela es unespacioenel que están presentes múltiples individuos, con sus construcciones identitarias, este texto tiene la siguiente pregunta: ¿Cuál es son las contribuciones de las narrativas mediáticas para problematizar las sexualidades en el espacio escolar? Para ello, apoyamos nuestras reflexiones teóricas a partir de los Estudios Culturales, por entenderlos como un campo que analiza los medios como un terreno de disputa, en el cual los grupos sociales luchan por el dominio. En el transcurso del texto, defendemos la idea de que, al llevar las narrativas mediáticas sobre las diferentes sexualidades al espacio escolar, contribuimos a una acción docente que valorice a los diferentes alumnos y alumnas que habitan el aula y, sin embargo, buscamos demostrarlo por medio del análisis de algunos personajes de la serie de Netflix, titulada Sex Educacion (2019). Concluimos así que la acción pedagógica con los medios de comunicación para discutir sexualidad, posibilita el proceso de visibilidad de esas múltiples formas de ser y estar en el mundo, Además de colaborar con una formación de profesores y profesoras comprometidas con una política cultural implica contemplar a todos los alumnos y alumnas en clase en sus dimensiones sociales y sexuales.

Palabras clave: Formación docente; Narrativas mediáticas; Sexualidad.

\section{Introdução}

Por mais que, nos últimos anos, no Brasil, exista uma série de projetos, no âmbito municipal e estadual, que têm como intuito proibir a discussão de gênero e sexualidade no espaço escolar, precisamos admitir que a sexualidade humana constitui um dos elementos de nossa identidade, pois, ela é uma dimensão da experiência social permeada por inúmeras questões e, por meio dela, acessamos um universo de desejos, crenças e valores, articulando a subjetividade dos indivíduos e dos grupos sociais a que pertencem. Todavia, os debates sobre a sexualidade humana, nos diferentes espaços, estão permeados por processos de hierarquização social. Sendo a escola uma das instituições sociais em que indivíduos estão inseridos, cada qual com sua sexualidade, esse texto tem como questão norteadora: Quais as contribuições das narrativas midiáticas para problematizar a sexualidade dos indivíduos no espaço escolar?

Um dos primeiros elementos para os quais precisamos chamar atenção é o fato de que as narrativas midiáticas veiculam os saberes sociais e, com eles, as representações identitárias. 
Como afirma Kellner (2001), há uma cultura veiculada pela mídia cujas imagens, sons e espetáculos ajudam a urdir o tecido da vida cotidiana, dominando o tempo de lazer, modelando opiniões políticas e comportamentos sociais, ainda, fornecendo o material com o qual as pessoas constituem sua identidade.

No entanto, para entendermos a importância da utilização dessas narrativas midiáticas, no espaço escolar, e, ainda, como elas colaboram para a formação docente e ação pedagógica, torna-se preciso problematizar estas narrativas, a partir das relações de cultura e poder nelas inseridas. Para isso, utilizaremos os contributos teóricos dos Estudos Culturais, por dois motivos: primeiro, porque defendemos as relações sociais como práticas de significação, produção e relação de poder que produzem e reproduzem identidades sociais; segundo, porque entendemos que a cultura que vivenciamos possibilita entender o que somos e quem somos, mesmo que de forma provisória.

Os Estudos Culturais, a partir das formulações de autores como Hall (1997), Costa (2000) e Giroux (2008), discutem a centralidade dos artefatos culturais, como as mídias e suas imbricações com as escolhas e preferências dos sujeitos sociais. Como destaca Costa (2000, p. 73), os Estudos Culturais auxiliaram a compreender que "[...] a mídia tem uma função na constituição das coisas que ela reflete". Assim, a educação e a formação docente também ocorrem em processos escolares e universitários, cotidianamente, também em relação aos discursos e as narrativas midiáticas que inscrevem modos de ser, de pensar e de agir em diferentes espaços e temporalidades.

Para os Estudos Culturais, a educação gera um espaço narrativo privilegiado para alguns/algumas estudantes e, ao mesmo tempo, produz, para outros/as um espaço que reforça a desigualdade e a subordinação. Corporificando formas dominantes de capital cultural, a escolarização, frequentemente, funciona para afirmar as histórias eurocêntricas e patriarcais, as identidades sociais e as experiências culturais dos/as estudantes de classe média, ao mesmo tempo que marginaliza e/ou apaga as vozes, as experiências e as memórias culturais dos/as assim chamados/as estudantes da "minoria". Para muitos/as estudantes, a escolarização significa vivenciar formas cotidianas de interação escolar, que são irrelevantes para suas vidas, ou sofrer a dura realidade da discriminação e da opressão, através de processos de classificação, de policiamento, de discriminação e de exclusão (BARTOLOME, 1994; FINE, 1991; ARONOWITZ; GIROUX, 1993; MACEDO, 1994; BRADY, no prelo apud GIROUX, 2008, p. 87).

Ao mostrar as potencialidades de interpretação dos Estudos Culturais, Giroux (2008) explicita as contribuições de uma formação que visibiliza pensar como as narrativas midiáticas, as análises culturais e as possibilidades de problematização desnaturalizam e 
contribuem para uma interpretação das experiências cotidianas. $\mathrm{O}$ intelectual nos explica que "[...] a pedagogia como forma de política cultural deve ser compreendida como um conjunto concreto de práticas que produzem formas sociais, através das quais diferentes tipos de conhecimento, conjuntos de experiências e subjetividades são construídas”. Assim, pensar a formação de professores estimulada pelos Estudos Culturais, com foco nas narrativas midiáticas sobre sexualidade, pressupõe refletir sobre o modo "[...] como certos aparatos de poder produzem formas de conhecimento que legitimam um tipo particular de verdade e estilo de vida" (GIROUX, 1997, p. 31).

Desse modo, a educação se torna um campo de atuação em que professoras e professores precisam discutir seus papéis e suas contribuições, além disso, "ensinar de um jeito que respeite e proteja as almas de nossos alunos e nossas alunas é essencial para criar as condições necessárias para que o aprendizado possa começar do modo mais profundo e mais íntimo" (HOOKS, 2013, p. 25). Inspirados por estas contribuições acerca de uma dimensão política e cultural da educação, pensamos a formação docente atrelada a elementos não escolares e às experiências que as narrativas midiáticas indicam, incitam e investem, na construção de representações sobre a sexualidade.

\section{Mídia e sexualidade: e as construções de narrativas}

Um dos ensinamentos que aprendemos como Kellner (2001), ao estudar a cultura da mídia, é o de que se trata de um terreno de disputa, no qual os grupos sociais lutam pelo domínio e, ainda, que os indivíduos vivenciam essas lutas por meio de imagens, discursos e espetáculos. Tudo isto nos faz afirmar que as narrativas midiáticas são marcadas por uma pluralidade de discursos que ora se tensionam, conflitam, negam-se e ora dialogam sobre as diferentes culturas, saberes, identidades e lógicas de ser.

As narrativas midiáticas podem constituir um entrave para a democracia quando reproduzem os discursos reacionários, promovendo racismo, preconceito de sexo, gênero, sexualidade, idade, classe e outros. Entretanto, estas mesmas narrativas podem propiciar avanço dos interesses dos grupos dominados, quando ataca coisas como as formas de segregação racial ou sexual, ou quando, pelo menos, as enfraquecem com representações múltiplas sobre raça, sexo, gênero e sexualidade (KELLNER, 2001).

Podemos afirmar que uma das características da mídia, enquanto campo de luta pelas representações, é dar lugar à pluralidade das vozes sociais, expressando a multiplicidade de 
formas culturais e incluindo os que parecem viver à margem da sociedade. O campo midiático, enquanto lugar que veicula imagens, sons e espetáculos sobre a realidade, contribui para a definição de papéis e da afirmação de valores e sentidos na sociedade.

O conjunto de representações gerado na sociedade é trabalhado pela mídia que as organiza, de acordo com um sistema próprio de estratégias comunicativas. Ao definir as estratégias, muitas vezes a mídia cria e reforça representações do discurso social hegemônico. De acordo com Estudos Culturais, um dos pressupostos das narrativas midiáticas é o de fornecer o maior número de "pontos de vista" possíveis acerca de determinado tema. Este processo pode ser entendido como desnaturalização, que em consonância com as formulações de Kellner (2001), permite ao público resistir aos significados e às mensagens dominantes e criarem seu próprio modo de apropriar-se das narrativas sociais.

No entanto, entendemos que diversos temas sociais veiculados pela mídia são compreendidos como naturais e não como socialmente construídos por meio dos múltiplos discursos nas narrativas sociais. Esta visão condiciona também a forma como os indivíduos e os comportamentos são compreendidos, ou seja, sob uma ótica essencialista e universalizante, que não leva em conta os processos culturais, historicamente, construídos nas sociedades, tomando-os pelo viés da "natureza", que se fundamenta em perspectivas do pensamento psico-biomédico, via de regra utilizado para dar conta de fenômenos sociais (COSTA, 2000).

Essa forma naturalizante de compreender sujeitos e os comportamentos sociais, por parte da mídia, é o eixo que norteia a construção de sentidos sobre a representação das relações de gênero e sexualidade, na sociedade contemporânea. Deste modo, ela se funda num padrão normativo ocidental hegemônico que, além de partir do pressuposto da heterossexualidade compulsória, hierarquiza e atribui valores aos sujeitos, às feminilidades, às masculinidades, aos arranjos socio-afetivos e familiares, ainda, à sexualidade e às relações de poder, por meio deste conceito pautado na visão clínico-patológica, construído na modernidade. Sobre esta perspectiva é que estão fundados os valores responsáveis pela produção da maioria das narrativas e dos sentidos sobre comportamentos dos indivíduos e grupos na sociedade, veiculada pela mídia e que constitui, assim, a ideia do que é normal, certo e correto.

A educação que recebemos acerca das práticas sexuais é heterocentrada e, seguindo uma dinâmica do pensamento hétero, tal como nos explica Monique Wittig (1980, s/p.), é uma naturalização que, por meio de discursos "negam-nos toda a possibilidade de criar as nossas próprias categorias”. Mombaça (2017, p. 302) explica a atuação do poder na 
ficcionalização que produz o mundo. Assim, compreendemos que "[a]s ficções de poder se proliferam junto a seus efeitos, numa marcha fúnebre celebrada como avanço, progresso ou destino incontornáveis".

$\mathrm{Na}$ mídia brasileira, por mais que tenhamos uma hegemonia na forma de pensar e perceber a sexualidade, essa experiência toma forma no plural, posto que vários componentes ou subsistemas têm sido identificados como concorrendo para problematizar a sexualidade humana. Conforme Parker (1991), é possível identificar, ao menos, quatro lógicas narrativas que se encontram em abrangência arraigadas nas representações midiáticas sobre a sexualidade no Brasil:

A primeira forma de narrar a sexualidade está ligada à hierarquia de gênero que, situada no contexto de uma ordem social patriarcal, oferece, em seus cálculos de feminilidade/masculinidade ou passividade/atividade, a base para um complexo sistema de dominações simbólicas, estabelecendo relações hierárquicas não apenas entre homens e mulheres, mas entre uma série mais ampla de tipos classificatórios.

Essa lógica narrativa desconsidera a diferenciação entre os conceitos de gênero, sexualidade e sexo, utilizando-os como sinônimos, invisibilizando o fato de que são conceitos e práticas inter-relacionados, mas não são a mesma coisa e, portanto, é imprescindível que esta relação seja percebida e trabalhada no âmbito da educação escolar (LOURO, 2008).

A segunda lógica narrativa sobre a sexualidade humana veiculada midiaticamente é o discurso científico sobre sexualidade, que emergiu nos finais do século XIX e permanece atuante, até os nossos dias. O referido discurso traz uma ideia de verdade sobre a biologiafisiologia dos corpos e prescrições para uma vida sexual saudável, focando, ao mesmo tempo, no "eu" sexual e na reprodução e, assim, mapeia "racionalmente" as "anormalidades", criando outra forma de classificar as sexualidades, padronizando o universo da vida sexual dita "saudável”. Esta lógica narrativa dá ênfase só às questões biológicas da sexualidade humana, não levando, entretanto, em consideração, que esta sexualidade não é determinada pelo sexo do sujeito social e que a sexualidade humana pode sofrer arranjos e desarranjos, a partir de influências sociais, possibilitando, assim, múltiplas formas de vivenciá-la (HALL, 1997).

Já a terceira narrativa midiática sobre a sexualidade humana está ligada à herança religiosa judaico-cristã, na qual a visão religiosa, com ênfase no pecado e na culpa, na implicação do corpo e seus atos para a alma, constrói um discurso da punição do corpo em prol do "salvamento" da alma. Desta forma, estabelece-se também uma forma única de vivenciar a sexualidade e, quem foge a essa regra, é tomado como o amaldiçoado e pecador. 
A lógica constitutiva dessa narrativa, de acordo com Foucault (1988), foi responsável pela maneira com que a sexualidade humana foi tratada ao longo da história, construindo processos de hierarquização social implementados a partir do gênero, sexo e sexualidade.

A quarta narrativa, atualmente vinculada pela mídia sobre sexualidade humana, traz redescrições de sentido para a sexualidade, como o discurso científico contemporâneo, em que o ser social se opõe ao natural, na disputa pelo que seria o sexo e sexualidade e como esta instância intervêm ou é apreendida na ordem do mundo. É a voz questionadora de movimentos sociais atuais, que tem, no sexo, um dos referenciais de luta, como o movimento gay e lésbico e também o movimento feminista (LOURO, 2008).

Essa perspectiva questiona a normatização da sexualidade humana e, com base nas formulações de Foucault, afirma que a normatização da sexualidade é constituída de práticas discursivas que, sistematicamente, formam os objetos de que falam. Assim, devemos estudar estes discursos "criadores", os interesses que os regem e buscar determinar seus objetivos.

Essas e outras narrativas, na arena midiática e no terreno social, se articulam, confrontam e dialogam na constituição de representações e práticas sobre a sexualidade humana. Tais representações estão enraizadas na sociedade brasileira e têm força na constituição dos discursos sociais e na disputa por representações. Muitas destas representações têm a mídia como principal difusor, outras estão lutando para ganhar espaço no universo representacional. Muitos são mais conservadores, outros mais questionadores do papel do sexo e sexualidade na organização do mundo social, todavia, alguns propõem e possibilitam estruturações de eventos mais equitativos e justos, outros continuam a vitimizar, de diferentes modos, os sujeitos sociais, pelo seu modo de vivenciar sua sexualidade, devendo, sob esta lógica, ser denunciados, questionados, tensionados, desconstruídos ou reordenados de modo a proporcionar relações sociais mais justas.

Dessa forma, concordamos com Kellner (2000, p.39) quando afirma que "quanto mais perspectivas incidem sobre um fenômeno, melhor poderá ser a percepção ou entendimento deste". Assim, compreendemos que, quanto mais diversas forem as representações que a mídia veicular sobre a sexualidade, maiores serão as possibilidades de entendimento e identificação destas pelos sujeitos sociais.

Diferentes interpretações e análises são possíveis na problematização do artefato da cultura midiática, por tratar de temas referentes ao espaço escolar, as relações afetivas e sexuais de adolescentes e as identidades e representações visíveis e vivíveis, por meio destas expressões. O produto tem elementos que podem contribuir para uma vida social e sexual 
complexa e de diferentes contribuições, assim como, pode interferir de forma a construir uma visão estereotipada de relações, práticas e interpretações da sexualidade.

\section{Narrativas da mídia sobre a sexualidade como estratégias políticas na formação docente}

$\mathrm{Na}$ atualidade, é fundamental que um docente, em suas ações pedagógicas, perceba que a sala de aula é um local em que as diferenças culturais borbulham, a todo instante, visto que o ambiente escolar é composto por seres humanos, com distintas formas de narrar o mundo e suas representações sobre este. As narrativas, circunscritas nas formas de existência dos discentes em sala de aula, conferem sentidos e representam as experiências individuais e coletivas, implicando em um processo contínuo de produção de identidades, que são posicionadas no interior dos diversos saberes sociais, de acordo com a compreensão que cada um de nós tem delas.

Pensar em como as narrativas midiáticas podem ajudar a constituir as identidades dos sujeitos sociais demanda questionar a nós mesmos: o que é identidade? A identidade é construída por elementos individuais e sociais, mas é na relação indivíduo-sociedade que ela se modula (SILVA, 2007). Neste sentido, o homem e a mulher são seres sociais e políticos, afetados por fatores externos tais como a cultura, a moral, a religião e a sexualidade. A identidade, portanto, não é um produto acabado. Ao contrário, é resultante da tensão estabelecida entre os elementos internos e externos e oferece possibilidades de ser, agir e pensar que auxiliam na formulação das características individuais

Ao considerarmos a sexualidade humana como um dos elementos para pensarmos a formação da identidade dos sujeitos sociais, é importante entendermos que a vivência da sexualidade é individual e pode ser pensada como uma questão psicológica. Todavia, esta experiência é complexa e se mistura com a experiência social, constituindo o elemento identitário dos grupos sociais. Desta forma, as diferentes sexualidades proclamam as identidades, as formas de apresentar-se e reconhecer-se e estas exigem, não só a construção social de pertença, mas também a elaboração e a interiorização das características valorativas do modo de ser de cada indivíduo.

Assim, ao levar as narrativas midiáticas relativas às diferentes sexualidades para o espaço escolar, estamos fornecendo elementos para que os sujeitos sociais pensem e repensem suas identidades sociais, já que estas narrativas nos ensinam as histórias, os saberes pelas quais vivemos e, ao mesmo tempo, oferece os meios para refletir, questionar e criticar 
nossas próprias representações sobre sexualidade como conceito único, pronto e acabado. Ou seja, as narrativas midiáticas sobre as diferentes sexualidades e formas de vivenciá-las nos abrem espaços de visibilidade que estão sujeitos à compreensão de que há múltiplas representações.

Para Larrosa (1994), as narrativas são processos que conferem sentindo aos saberes sociais, pois são formas às quais os sujeitos imprimem uma ordem lógica e temporal às suas sensações, percepções, vivências e recordações individuais. Desta maneira, se as diferentes narrativas sobre a sexualidade humana adentrarem o espaço escolar, constituiremos uma educação escolar que valorizará os múltiplos sujeitos que estão nas salas de aulas.

A multiplicidade de narrativas sobre a sexualidade no espaço escolar será entendida como construção histórica e cultural, constituída pelas experiências de vida das pessoas, estando, assim, em consonância com as formulações de Foucault (1988). Este pensador afirma que a sexualidade é o nome que pode ser dado a um dispositivo histórico, não à realidade subterrânea que se apreende com dificuldade, mas à grande rede da superfície em que a estimulação dos corpos, a intensificação dos prazeres, a incitação ao discurso, a formação dos conhecimentos, o reforço dos controles e das resistências encadeiam-se uns aos outros, segundo algumas estratégias de saber e de poder.

Nessa perspectiva, formar docentes para trabalhara sexualidade no espaço escolar, enquanto constructo histórico é, no processo de problematização, oportunizar discussões passíveis de arranjos múltiplos permitindo, assim, que as diversas sexualidades existentes sejam valorizadas nas suas diferenças e rompendo com a pedagogia do ocultamento que cerca essa temática.

[...] os educadores estão mal preparados quando confrontam concretamente a diversidade [...]. Para ensinar eficazmente um corpo discente diverso, tenho de aprender esses códigos [culturais diferentes]. E os alunos também têm. Esse ato por si só transforma a sala de aula. A partilha de ideias e informações nem sempre progride tão rápido quanto poderia progredir num contexto mais homogêneo. Muitas vezes, os professores e os alunos no contexto multicultural têm de aprender a aceitar diferentes maneiras de conhecer, novas epistemologias. (HOOKS, 2013, p. 59).

Dessa maneira, formar professoras e professores que se envolvam com as diferenças culturais e pensem seus papéis na interpretação e crítica das representações midiáticas, exige o comprometimento em revisar os conhecimentos da Educação e ofertar outras perspectivas de análise das dimensões sociais e culturais. Giroux (1997, p. 39) explica que o conhecimento 
é resultado de processos e construções de formas e conteúdos e "[...] é produzido, apropriado e transformado dentro dos ambientes sociais e históricos específicos".

Foucault (2009, p. 9) explica que, nas sociedades, “[...] a produção do discurso é, ao mesmo tempo, controlada, selecionada, organizada e redistribuída por certo número de procedimentos que têm por função conjurar seus poderes e perigos, dominar seu acontecimento aleatório, esquivar sua pesada e temível materialidade". Assim, as narrativas midiáticas constituem um movimento de organização dos modos de saber e a formação docente, comprometida com uma análise e problematização da realidade, precisa dialogar e contribuir para a crítica dos processos de naturalização de modos de vida específicos, em detrimento das pluralidades dos modos de ser e viver.

Conhecer a si e ao outro perpassa o processo de sentidos atribuído pelas narrativas que contamos, ouvimos e lemos. A produção de sentindo não é uma atividade intra-individual, mas sim, uma prática social, essencialmente, dialógica, o que implica em entender que as narrativas constroem realidades sociais e processos de identificação. A produção de saberes também é construída por um cruzamento de narrativas, que ora se combinam e ora se negam.

Nesse sentindo, a compreensão das narrativas das mídias sobre sexualidade no espaço escolar, como uma estratégia política, demanda a compreensão do que Jovchelovitch (2008) chama de dimensões das representações, ou seja, é necessário perguntar sobre quais condições particulares um sistema de saberes é produzido e sustentado. Assim, as dimensões das representações do saber se manifestam de várias formas e contribuem para pensar as múltiplas narrativas, suas criações, suas produções e divulgações, contribuindo para a visibilidade da diversidade de ser, estar e agir no mundo. Logo, a valorização das narrativas sociais implica no questionamento de conceitos únicos e na hierarquização de uma lógica de saber sobre outras.

Para Jovchelovitch (2008), todo saber é sempre sustentado por uma comunidade e deve ser compreendido no plural. Não há uma única forma de narrá-los, mas muitas. Desta forma, o saber é um ato que depende de quem sabe, o que sabe, por que sabe, para que alguém sabe. O saber é forma heterogênea e maleável, cuja racionalidade e lógica não se definem por uma norma transcendental, mas em relação ao contexto social, psicológico e cultural de uma comunidade.

O saber é móvel, transforma-se, assume novas e diferentes roupagens ao ser inserido em campos epistemológicos variados, e essas transformações no saber e na forma com que ele é narrado, têm origem nas relações sociais em jogo e na forma como queremos que os grupos 
sejam representados. As experiências humanas, inclusive a sexualidade, são construções e interpretações que não são únicas e nem verdadeiras, mas subjetivas, relativas e políticas. A sexualidade assume diversas formas de expressão, formas essas que estão relacionadas às demais dimensões da vida social, no que se relaciona com a produção e a reprodução dos valores que constituem a vida coletiva. Em outras palavras, cada sexualidade expressa visões particulares, significados próprios de determinadas culturas e insere-se na disputa pela manutenção do poder. Sendo assim, as narrativas têm como característica construir processos de valorização ou desvalorização dos múltiplos sujeitos e dependerá sempre dos interesses que estão em jogo no momento em se narra.

Valorizar os múltiplos sujeitos sociais, pressupõe uma ação que não se limite apenas a reconhecer que os saberes são diferentes, mas é necessário entender que suas lógicas constitutivas também são diferentes, visto que suas dimensões representativas atendem interesses diversos. Santos (2006) afirma que isto só será possível se for adotada uma pedagogia que valorize a alteridade.

Gusmão (1997, p.16 -17) argumenta que a alteridade é possível somente "num processo inverso ao da homogeneização proposta pelo campo político das relações entre povos e culturas distintas". Compreender o outro significa "relativizar o próprio pensamento para construir um conhecimento que é outro". Enfim, o processo de "ver-se" e "ver o outro" exige um esforço para entender a cultura do outro e compreender as suas categorias de percepção dentro de um contexto histórico concreto, tanto no senso comum quanto no conhecimento científico.

Para estabelecer um processo de alteridade entre os múltiplos sujeitos, é preciso reconhecer o "outro" e entender que ser diferente ou fazer diferente não pode ser critério para exclusão. Por isso, os conceitos homogêneos, estáveis e permanentes devem ser questionados, e as certezas que foram, socialmente, construídas devem ser fragilizadas e desvanecidas. É imperativo, portanto, desconstruir, pluralizar, ressignificar e reinventar identidades, subjetividades, saberes, valores, convicções e horizonte de sentidos. Somos obrigados a assumir o múltiplo, o plural, o diferente e o híbrido, na sociedade como um todo (CANDAU, 2005).

A diversidade é um componente do desenvolvimento biológico e cultural da humanidade. Ela se faz presente na produção de práticas, saberes, valores, linguagens, técnicas artísticas, científicas, representações do mundo, experiências de sociabilidade e de aprendizagem. Todavia, há uma tensão nesse processo. Por mais que a diversidade seja um elemento constitutivo do processo de humanização, há uma tendência nas culturas, de um modo geral, 
de ressaltar como positivos e melhores os valores que lhe são próprios, gerando um certo estranhamento e, até mesmo, uma rejeição em relação ao diferente. É o que chamamos de etnocentrismo. Esse fenômeno, quando exacerbado, pode se transformar em práticas xenófobas (aversão ou ódio ao estrangeiro) e em racismo (crença na existência da superioridade e inferioridade racial) (GOMES, 2007, p.18).

Construir os caminhos para valorizar os sujeitos socialmente não pode ser só um exercício de perceber os diferentes ou de tolerar o "outro". Antes de tolerar, respeitar e admitir a diferença, é preciso explicar que a mesma foi produzida, historicamente, e quais são os jogos de poder estabelecidos por ela. Como nos alerta Silva (2000), a diversidade biológica pode ser um produto da natureza, mas não podemos afirmar o mesmo sobre a diversidade cultural. De acordo com o autor, a diversidade cultural não é um ponto de origem. Ela é, em vez disso, um processo conduzido pelas relações de poder constitutivo da sociedade, que estabelece o "outro" como diferente do "eu" e o "eu" diferente do "outro", como uma forma de exclusão e marginalização.

Como afirma Jovchelovitch (2008),há um potencial emancipatório em reconhecer as diversas lógicas de saberes que demanda, necessariamente, em reconhecer e valorizar os múltiplos sociais envolvidos, transformando as narrativas que são, geralmente, centradas no "eu", ou no "outro", em narrativas centradas no "eu" e "outro", construindo relações valorativas, constituindo assim o "nós".

Dessa forma, é necessário compreender que, no espaço escolar, a sexualidade é um elemento determinante na constituição dos sujeitos, pois os caminhos de nossa sexualidade são constituidores de formas de expressão, de prazer, de visibilidades e relações sociais e estão recobertos de símbolos, rituais e valores que estruturam e dão coesão às práticas e instituições sociais, ou seja, nossos hábitos sexuais dependem da construção social das relações entre os seres humanos.

Nesse sentido, não se pode perder de vista que ter determinada prática sexual carrega mais elementos do que simplesmente os comportamentos individuais em si. As diversas práticas sexuais estão, historicamente, entrelaçadas por relações sociais, identidades sociais e formas de inserção no mundo público.

As narrativas midiáticas podem colaborar com o processo de visibilidade dessas múltiplas sexualidades, quando demonstram, como afirma Louro (2008), que há muitas formas de experimentar prazeres e desejos, de dar e receber afeto, de amar e de ser amada ou amado, que são ensinadas na cultura e que são diferentes de uma cultura para outra, de uma época ou de uma geração para outra. E hoje, mais do que nunca, essas formas são múltiplas. 
As possibilidades de viver os gêneros e as sexualidades ampliaram-se. As certezas acabaram e tudo isso pode ser fascinante, rico e também desestabilizador, mas não há como escapar a este desafio.

O único modo de lidar com a contemporaneidade é, precisamente, não se recusar a vivê-la. E, quando se trata da discussão sobre a sexualidade humana no espaço escolar, é fundamental que os docentes, em sua formatação, entendam a multiplicidade de suas manifestações na vida dos sujeitos sociais. Tendo isso em vista é que nos propomos, ainda neste texto, demonstrar as contribuições que uma narrativa midiática chamada Sex Education (2019) pode oferecer para a compreensão da constituição da diversidade sexual e os processos de hierarquização em que ela está inserida.

\section{Narrativas sobre a sexualidade em Sex Education (2019)}

O seriado Sex Education, de produção da Netflix, dirigido por Bem Taylor e Kate Herron, queestreou no dia 11 janeiro de 2019. A classificação dessa narrativa midiática,de acordo com a diretriz legislativa e as definições do Estatuto da Criança e do Adolescente (ECA), Lei $\mathrm{N}^{\mathrm{o}}$ 8069/90, é acima de 14 anos. O seriado tem, atualmente, 396 minutos, é catalogado nos temas comédia e drama e trata da história de um adolescente, filho de terapeutas sexuais, virgem e com ansiedadee que, pela experiência de viver com a mãe e suas relações profissionais e sexuais, inicia-se, com a ajuda de uma das garotas rebeldes do colégio, numa clínica clandestina que ajuda os alunos que estão com problemas sexuais, em troca de dinheiro.

Diferentes interpretações e análises são possíveis na problematização deste artefato da cultura midiática, por tratar de temas referentes ao espaço escolar, as relações afetivas e sexuais de adolescentes e as identidades e representações visíveis e vivíveis por meio dessas expressões. O produto tem elementos que podem contribuir para uma vida social e sexual complexa, assim como pode interferir de forma a construir uma visão estereotipada de relações, práticas e interpretações da sexualidade.

Por exemplo, as relações homossexuais, ao serem entendidas como aquelas que fogem às normas estabelecidas, são representadas de forma estereotipada e, ao mesmo tempo, nos auxilia a questionar as inscrições culturais e as práticas representacionais de personagens homossexuais nas cenas do referido seriado e, ainda, refletir sobre qual o local social que a 
homossexualidade ocupa quando confrontada pela norma posta pela cultura heterocêntrica em que vivemos.

Apesar de a série contemplar múltiplas formas de manifestação da sexualidade humana, os personagens que escolhemos para analisar estão no seriado para constituir explicações acerca da dimensão binária e opositora entre masculinidade/feminilidade e em corpos machos com dimensões de poder que se inscrevem nas lógicas racial e econômica que separam os sujeitos. Além desses elementos que se configuram pelas diferenças, Eric e Adam têm, também, uma diferença afetiva: as relações familiares e suas interações sociais.

Eric é negro, gay, efeminado, impopular na escola e tem uma família grande, com muitas irmãs, pai e mãe. Uma família barulhenta e intrometida que o incomoda, em diferentes momentos. Eric é amigo do protagonista Otis, desde a infância e, em diferentes momentos, mostra-se companheiro, afetivo, disponível e animado. Eric é uma pessoa que se dedica muito às relações e gostaria de ser aceito pelas pessoas. Entretanto, na escola, na família, na rua, o personagem passa por diversas situações de exclusão, opressão e violência (SEX EDUCATION, 2019).

Parte dessas violências e agressões, assim como a humilhação, são ações feitas por Adam. O agressor é branco, heterossexual, masculino, silencioso, rude e mau aluno, é muito agressivo, ofensivo e incomoda as pessoas em diferentes momentos. Adam é filho do diretor do colégio, um homem que se aparece como alguém pouco amável e que tem mais afeto pelo aluno desportista famoso, Jackson, do que pelo próprio filho. Adam tem pouco afeto, mas, no primeiro episódio do seriado, aparece namorando e tendo dificuldades para gozar com a namorada porque seu pênis é muito grande. Adam representa elementos de uma lógica masculina central e privilegiada pela narrativa social (SEX EDUCATION, 2019).

As posições de sujeito representadas por Eric e Adam nos mostram diferentes possibilidades das masculinidades que são inscritas nas sociedades heterocentradas. Isso revela o fato de que "o hegemônico e o subalterno surgiram em uma interação mútua, mas desigual em uma ordem social e econômica dividida em gêneros" (KIMMEL, 1998, p.105). A compreensão desta lógica também auxilia nossa leitura sobre os modos de agir e de ser que são possíveis para determinados sujeitos, por meio da visibilidade que nos inscrevem. Além de pensar a representatividade é, também, necessário avaliarmos os modos como as mídias nos educam, nas narrativas em que nos inscrevem, a partir de uma lógica cis-heteronormativa.

Assim, existem imposições que instituem e constituem modos de ser e de agir que inscrevem as lógicas de relações de poder. Kimmel (1998, p. 105) trata da construção das 
masculinidades e dos modos de se perceber a compreensão de ser masculino, bem como tais representações "[...] variam de cultura a cultura [...] em qualquer cultura no transcorrer de um certo período de tempo [...] [...] em qualquer cultura através de um conjunto de outras variáveis, outros lugares potenciais de identidade e [...] no decorrer da vida de qualquer homem individual".

Essas dissidências de masculinidades entendidas como menores, sem importância ou, até mesmo, como não masculinas mostram porque "[v]iver no armário, e então sair dele, nunca são questões puramente herméticas. As geografias pessoais e políticas são as mais imponderáveis e convulsivas do segredo aberto" (SEDGWICK, 2007, p. 39). Masculinidade e homossexualidade são atravessadas por estruturas de poder/saber que hierarquizam e delimitam as experiências das masculinidades homossexuais em diferentes espaços/tempos.

A masculinidade entendida por hegemônica "deve ser provada, e assim que ela é provada, ela é novamente questionada e deve ser provada mais uma vez; a busca por uma prova constante, durável, inatingível [...]” (KIMMEL, 1998, p. 111). Este movimento representa a interação entre Eric e Adam durante o percorrer dos episódios do seriado Sex Education. O valentão Adam, em diferentes momentos do seriado, aparece ameaçando, agredindo, diminuindo, ofendendo e oprimindo o delicado Eric, que se apresenta como efeminado. Kimmel (1998, p. 113) explica que “[...] a principal maneira pela qual os homens buscavam demonstrar a aquisição bem-sucedida de masculinidade era através da desvalorização de outras formas de masculinidades, posicionando o hegemônico por oposição ao subalterno, na criação do outro" (KIMMEL, 1998, p.113). Essa dimensão de masculinidade alimenta uma lógica tóxica de violência aos sujeitos que não seguem os padrões heteronormativos.

Afinal, “[o]s homens gays são bichinhas passivas e efeminadas, assim como são sexualmente insaciáveis e predatórios" (KIMMEL, 1998, p. 116). As representações de Eric são produtos de uma lógica de escárnio e de um humor que macula a feminilidade inscrita em corpos masculinos homossexuais. As possibilidades de ser que Eric traz para as telas, em suas cores e nas suas formas de brincar com o humor e a violência que inscrevem em nossas possibilidades de ser gay, é que incomodam, por desnaturalizar a lógica de uma heterossexualidade natural.

Assim, para além de pensar apenas o papel de Eric ou de Adam como oposições de masculinidades, também é necessário pensar o quão palatável é a heterossexualização da homossexualidade, quando esses personagens são postos em lógicas de complementaridade e 
que se valem de dimensões estereotipadas de feminilidades e masculinidades para a reformulação de padrões sexuais. Tendo em vista que a heteronormatividade é compulsória, a lógica organizada para a experiência das homossexualidades será aceita, desde que se cumpra com as idealizações que fazem parte do "conjunto de mitos heterossexuais", assim, estamos imersos em "um sistema de signos que usa figuras de retórica" (WITTIG, 1980, p. 9).

A autora nos diz da necessidade de estudar essas figuras de representação que inscrevem as opressões de lésbicas, assim como Rich (2010, p. 35) explica que "[...] o fracasso de examinar a heterossexualidade como uma instituição é o mesmo que fracassar ao admitir que o sistema econômico conhecido como capitalista ou sistema de casta do racismo são mantidos por uma variedade de forças, incluindo tanto a violência física como a falsa consciência”. Entender que este sistema produz modos de nos posicionar como sujeitos não heterossexuais, também é perceber como a visibilidade funciona e como podemos provocar outras leituras desta realidade porque "os subalternos falam é com a clareza que somente a visibilidade tem" (KIMMEL, 1998, p. 117).

Wittig (1980, p. 6) nos provoca ao explicar que “[...] o pensamento hétero continua a afirmar que é o incesto, e não a homossexualidade, o seu maior tabu. Assim, pelo pensamento hétero, a homossexualidade não passa de heterossexualidade". Compor casais entre agredido e agressor, naturalizar a lógica de violência que inscreve a cis-heterossexualidade, masculina, branca e de classe abastada, que está presente nas lógicas de privilégio do poder é, também, indicar que "[...] o caráter opressivo de que se reveste o pensamento hétero na sua tendência para imediatamente universalizar a sua produção de conceitos em leis gerais que se reclamam de ser aplicáveis a todas as sociedades, a todas as épocas, a todos os indivíduos" (WITTIG, 1980, p. 6).

Albuquerque Junior (2010, p. 45) nos fala sobre a diferença entre os amores homossexuais e os amores heterossexuais. Ao explicar sobre estas diferenças, o autor nos explica que os primeiros "seriam amores que não têm tempo ou dos que não têm tempo a perder”. Assim, “[...] as relações homossexuais, por sua instantaneidade, vão alimentar fantasias acerca do que já se passou". O sexo como prática homossexual, realiza-se em outros modos de contato, "um ato sexual em que a boca esteve ocupada com outras práticas que não a da fala, pode dar origem, no tempo seguinte, a uma proliferação narrativa, uma miríade de significações” (ALBUQUERQUE JUNIOR, 2010, p. 46).

A inadaptabilidade para ser e agir e as desestabilizações, fazem parte da lógica heteronormativa que é alimentada por uma ficção da masculinidade heterossexual e pela 
violência que se aplica sobre corpos não heterossexuais. Mombaça (2017) nos diz da organização do sistema de violência que infringe atos de agressão sobre os corpos não normatizados e normalizados e nos ensina acerca da lógica de subserviência. $\mathrm{O}$ amor que nos aparece para expressar as possibilidades não heterossexuais é um amor sofrido e violento.

O poder opera por ficções, que não são apenas textuais, mas estão materialmente engajadas na produção do mundo. As ficções de poder se proliferam junto a seus efeitos, numa marcha fúnebre celebrada como avanço, progresso ou destino incontornáveis. O monopólio da violência é uma ficção de poder baseada na promessa de que é possível forjar uma posição neutra desde a qual mediar os conflitos. (MOMBAÇA, 2017, p. $302)$.

A representação dessa relação entre Adam e Eric e, ao mesmo tempo, as possibilidades de ser que Eric apresenta durante os episódios e as cenas reforçam uma lógica que não marca possibilidades outras e, mesmo ao pensarmos em dimensões diferentes, estamos diante de uma educação sexual que heterossexualiza representações. Outras possibilidades também podem derivar de corpos que não cumprem com a masculinidade hegemônica uma vez que diferentes formas de ser são possíveis.

Ainda que Adam, em momentos distintos, seja indicado como alguém que pode ter sensibilidade, fragilidade e como alguém que não precisa reforçar os estereótipos, ainda assim, o temos como o exemplo de representação valorizada e, de certo modo, aceita como ideal da masculinidade. Em outro ponto, a figura da homossexualidade também é revista num personagem que é rude com Eric em diferentes momentos, expressando que ser homossexual não nos faz sensíveis às dores e aos modos de ser outros.

Até mesmo essas representações diferentes de homossexualidades não colocam em voga a discussão de uma possibilidade outra de ser homossexual. As representações de feminilidades, delicadezas, os corpos outros, negros e efeminados, são infringidos por lógicas de violência e expostos como corpos, gestos e afetividades a serem destituídas de valor. Estar na posição de quem aceita sofrer a violência que o outro infringe a você como a única forma de ser reconhecido como sujeito de direito é aceitar que o afeto direcionado à bicha é a violência.

A masculinidade tóxica como projeto de poder deve ser abordada em qualquer discussão sobre a distribuição social da violência. A violência masculina é uma arma transversal de normalização de gênero e controle social. Ela afeta não apenas mulheres cis e corpos não heterossexuais e trans, mas também os próprios homens cisgêneros que tem que alcançar esses graus ideais de virilidade a fim de cumprir com aquilo que a normalidade de 
gênero requer. Entretanto, essa distribuição desigual da violência - que constrói corpos cis-masculinos como intrinsecamente viris - é responsável, numa escala micropolítica, pela manutenção do medo com base das experiências trans, dissidente sexual e feminina para com o mundo. (MOMBAÇA, 2017, p. 303).

Criar outras formas de agir é parte do rompimento com as experiências de violência que nos inscrevem. Eric traduz essa ressignificação, característica das formas de contestação da cultura gay, que deveria modificar as relações e criar outras "práticas de si e novas relações com os outros, que poderiam servir de modelos alternativos àqueles imperantes na sociedade ocidental contemporânea" (ALBUQUERQUE JUNIOR, 2010, p. 50). Há ainda uma parte no seriado em que Eric mostra como a violência incide sobre os corpos efeminados e mostra como isso fragiliza nossas interações. Seu sofrimento representado, é vivido de formas diferentes por nós como Mombaça (2017, p. 305) narra que "andar pelas ruas pode ser um evento difícil quando suas roupas são consideradas 'inapropriadas' e sua presença mesma é lida como ofensiva pelo modo como você age e aparenta". Assim, somos ameaçadas e ameaçados pela violência antibicha. Eric mostra como a violência infringe uma dor que destitui nossas cores, nossas risadas e apaga nossas formas de vida.

Após uma agressão, a bicha sente que deveria se proteger. Nossa culpa é atrelada a um movimento moralista que inscreve em nossos corpos e subjetividades a responsabilidade por uma violência que nos mata em diferentes momentos. "Redistribuição da violência é um projeto de justiça social em pleno estado de emergência e deve ser performada por aquelas para quem a paz nunca foi uma opção” (MOMBAÇA, 2017, p. 305). Eric nos mostra uma outra representação ao retomar suas cores e refazer seus gestos. Pinta-se, veste-se e vai à festa.

Eric nos ensina sobre resistência - como o ato de negociação que infringe sobre as relações de poder e outras práticas como a redistribuição da violência - ao ser abordado pelo pai, na entrada da festa quando o homem negro silencioso e recatado pergunta para o filho se aquilo, ou seja, pintar-se, vestir-se e mostrar-se era necessário. Eric afirma ao pai que aquele com as pinturas, com as cores e com os gestos é quem ele é. O pai está sendo importunado por um carro que buzina para que ele tire o veículo dele do caminho. Ele grita em resposta dizendo que já mandou o incomodado esperar. Retorna a Eric e diz: "acho que estou aprendendo a ser corajoso como meu filho" (SEX EDUCATION, 2019). Outras formas de ser precisam ressignificar os modos como compreendemos nossas representações. Desnaturalizar e ressignificar são práticas de problematização. 
Eric é uma figura representativa ambivalente. Uma outra forma de compreender a masculinidade efeminada engendrada em um relacionamento heterossexualizado, da homossexualidade. Foucault (2006) nos explica que o corpo é constituído como superfície dos acontecimentos e lógicas inscrevem modos de pensar e viver com o corpo, que inscrevem ações e processos históricos. Ao mesmo tempo, Wittig (1980, p. 10) provoca-nos ao dizer que “as lésbicas não são mulheres".

Destituir-se dos padrões heterossexuais normativos e compulsórios, redistribuir a violência, ressignificar nossas lógicas de amor, sexo e prazer são demandas contemporâneas para a formação docente. Essas representações nos mostram que, ao abrirmos espaços para outros modos de vivenciar as sexualidades, a todo momento, precisamos mostrar como a sociedade naturaliza e educa para a heterossexualidade. Os produtos midiáticos corroboram com uma narrativa naturalizadora das experiências que coadunam nos mitos heterossexuais.

Desse modo, reconhecer a heterossexualidade como narrativa constituída no ideal de normalidade é um modo de desestabilizar os sentidos prontos deste discurso e incomodar outras formas de pensar. Outras dimensões são possíveis, ao compreendermos que a categoria mulheres e lésbicas não se confundem ou que os amores homossexuais têm outra lógica temporal e, ainda, que nossa vida é outra. Descontinuar e interromper modos de pensar e de agir, confundir a estrutura e gerar diferentes dimensões de afeto, de sexo e de representações corroboram para táticas provocativas de outras formas de ser. Eis nossa luta. Mombaça (2017, p. 309) diz que "[n]ão há salvação. Isso aqui é uma barricada! Não uma bíblia” ao tratar da sua contribuição acerca da leitura sobre a redistribuição da violência. Sabemos fazer barricadas, sensibilizamos outras formas. Ser vida outra é criação.

\section{Considerações}

A construção do processo identitário dos múltiplos sociais perpassa necessariamente pelo reconhecimento das diversas sexualidades. Construções de formas de pensar que permitam perceber a multiplicidade da sexualidade humana demandam o constante questionamento das narrativas únicas, das normas e das condutas sociais hierarquizadas, fazendo duvidar do que foi e é afirmado como natural e questionar as narrativas préestabelecidas como verdades.

Embora com limitações, a pluralização das narrativas sociais sobre a sexualidade humana no espaço escolar, assim como os intercâmbios de saberes em que se leve em 
consideração o "eu e "outro" como sujeitos em relação com lógicas distintas, pode levar ao reconhecimento das diversas identidades culturais existentes e à construção de processos de reconhecimento das diferentes experiências vivenciadas, possibilitando que os diferentes sujeitos sejam valorizados e respeitados em todas suas características identitárias.

Em suma, a problematização das narrativas midiáticas, sexualidade e a abertura do espaço escolar em relação a estas narrativas, permitem construir os caminhos, no sentido de valorizar os sujeitos socialmente, constituindo-se em narrativas sociais e midiáticas que, para além de tolerar, respeite e admita as diferenças de modos de ser e estar no mundo. Problematizar e dialogar com os discursos midiáticos nos permite, como professoras e professores, pensar os discursos e narrativas que sustentam uma lógica de invisibilidade e de padronização das relações afetivas e sexuais.

A possibilidade de formar docentes para pensar as dimensões de organização das narrativas e produção dos discursos midiáticos corrobora com as práticas docentes e propõe uma ação de contribuição para a discussão acerca do papel midiático de oferecer modelos prontos para serem reproduzidos e promove a necessidade de questionar os elementos midiáticos que expõem um modo correto de agir, ser e viver. A formação de professores e professoras comprometidas com uma política cultural implica também em ser e formar intelectuais que repensem as dimensões sociais e sexuais.

\section{REFERÊNCIAS}

ALBUQUERQUE JUNIOR, Durval Muniz de. Amores que não têm tempo: Michel Foucault e as reflexões acerca de uma estética da existência homossexual. in: RAGO, Margareth (Org.). Dossiê Foucault e as Estéticas da Existência - Revista Aulas, Unicamp: Campinas, 2010. (41-58).

ANDRADE, Paula Deporte de. Pedagogias culturais - uma cartografia das (re)inveições do conceito. Tese (Doutorado em Educação). Universidade Federal do Rio Grande do Sul/UFRGS: Porto Alegre, 2016.

CANDAU, Maria Vera (org). Cultura(s) e educação: entre o crítico e pós-crítico. Rio de Janeiro: DP\&A, 2005

COSTA, Marisa V. Mídia, magistério e política cultural. In: COSTA, Marisa V. Estudos Culturais em educação: mídia, arquitetura, brinquedo, biologia, literatura, cinema. Porto Alegre, Ed. Universidade/UFRGS, 2000 
FOUCAULT, Michel. Sexualidade e Poder. In: "Sei to Kenryoku" (Sexualidade e Poder; conferência na Universidade de Tóquio, em 20 de abril de 1978, seguida de um debate). Gendai-shisô, junho de 1978. (56-76).

FOUCAULT, Michel. História da Sexualidade I: a vontade de saber. Rio de Janeiro: Graal, 1988.

FOUCAULT, Michel. A vida dos homens infames. In: FOUCAULT, Michel. Estratégia, poder-saber. Ditos e Escritos IV. Rio de Janeiro. Forense Universitária, 2003. (203-222).

FOUCAULT, Michel. Microfísica do Poder. 22. ed. Rio de Janeiro: Edições Graal, 2006.

FOUCAULT, Michel. A ordem do discurso: aula inaugural no Collège de France, pronunciada em 2 de dezembro de 1970. 19. ed. São Paulo: Loyola, 2009.

GIROUX, Henry A., os professores como intelectuais: rumo a uma pedagogia crítica da aprendizagem. Porto Alegre: Artes Médicas, 1997.

GIROUX, Henry A. Praticando Estudos Culturais nas Faculdades de Educação. In: SILVA, Tomaz Tadeu (org.). Alienígenas na sala de aula. Uma introdução aos Estudos Culturais em Educação. 7. ed. Petrópoles/RJ: Vozes, 2008.

GOMES, Nilma Lino. Indagações sobre currículo: diversidade e currículo. Organização do documento Jeanete Beauchamp, Sandra Denise Pagel, Aricélia Ribeiro do Nascimento. Brasília: Ministério da Educação, Secretaria de Educação Básica, 2007. Disponível em: http://portal.mec.gov.br/seb/arquivos/pdf/Ensfund/indag4.pdf Acesso em 20 dez. 2010.

GUSMÃO, N. M. M. Linguagem, cultura e alteridade: imagens do outro. Cadernos de Pesquisa da Fundação Carlos Chagas. São Paulo/Campinas, v. 107, n. 0, p. 15-21, 1999.

HALL, Stuart. A identidade cultural na pós-modernidade. Rio de Janeiro: DP\&A, 1997.

HOOKS, Bell. Ensinando a transgredir: a educação como prática da liberdade. Trad. Marcelo Brandão Cipolla. São Paulo: WMF Martins Fontes, 2013.

JOVCHELOVITCH, Sandra. Os Contextos do saber: representações, comunidade e cultura. Petrópolis, RJ: Vozes, 2008.

KELLNER, Douglas. A cultura da mídia: estudos culturais: identidade e política entre o moderno e o pós-moderno. São Paulo: EDUSC, 2001.

KIMMEL, Michael S. A Produção simultânea de masculinidades hegemônicas e subalternas. Horizontes Antropológicos. Ano 4. n. 9. Porto Alegre/RS, 1998. p.103-117.

LARROSA, J. Tecnologías do eu e educação. In: SILVA, T. T. (org) O sujeito da educação: estudos foucaultianos. Petrópolis: Vozes, 1994

LOURO. Guacira. L. Gênero, sexualidade e educação. Petropóles: Vozes 2008. 
LOURO, Guacira Lopes. Pedagogias da Sexualidade. In: LOURO, Guacira Lopes (Org.). O corpo educado: pedagogias da sexualidade. 2. ed. 2. reimp. Belo Horizonte: Autêntica, 2003. (7-34).

LOURO, Guacira Lopes. Um corpo estranho - ensaios sobre sexualidade e teoria queer. 2. ed. Belo Horizonte: Autêntica, 2013.

MOMBAÇA, Jota. Rumo a uma redistribuição desobediente de gênero e anticolonial da violência! In: PEDROSA, Adriano; MESQUITA, André. Histórias da sexualidade: antologia. São Paulo: MASP, 2017. (301-310).

PARKER, Richard. Corpos, prazeres e paixões: a cultura sexual no Brasil contemporâneo. São Paulo, Best Seller, 1991.

PRECIADO, Paul Beatriz. Testo Junkie. Sexo, drogas e biopolítica na era formacopornográfica. trad. Maria Paula Gurgel Ribeiro. São Paulo: n-1 edições, 2018.

PRECIADO, Paul B. O que é contrassexualidade? In: HOLLANDA, Heloisa Buarque de. (Org.). Pensamento Feminista: conceitos fundamentais. Rio de Janeiro: Bazar do Tempo, 2019. (411-420).

PRECIADO, Paul B. Multidões queer: notas para uma política dos “anormais. In:

HOLlANDA, Heloisa Buarque de. (Org.). Pensamento Feminista: conceitos fundamentais. Rio de Janeiro: Bazar do Tempo, 2019. (421-429).

RICH, Adrienne. Heterossexualidade compulsória e existência lésbica. Trad. Carlos Guilherme do Valle. Bagoas - estudos gays e lésbicos. N. 5: UFRN: Natal, 2010. (17-44). Disponível em: < https://periodicos.ufrn.br/bagoas/article/view/2309>. Acesso em: 04 dez. 2018.

SÁEZ, Javier; CARRASCOSA, Sejo. Pelo cu: políticas anais. Trad. Rafael Leopoldo. Belo Horizonte/MG: Letramento, 2016.

SANTOS, Boaventura de Souza. A gramática do tempo: para uma nova cultura política. São Paulo: Cortez, 2006.

SEDGWICK, Eve Kosofsky. A epistemologia do armário. Cadernos Pagu. v. 28. n. 19 Campinas, 2007 (19-54). Disponível em: http://www.scielo.br/pdf/cpa/n28/03.pdf. Acesso em: 09 jul. 2019.

SEFFNER, Fernando. A produção da diversidade e da diferença no campo do gênero e da sexualidade: enfrentamentos ao regime da heteronormatividade. In: KIRCHOF, Edgar Roberto; WORTMANN, Maria Lúcia; COSTA, Marisa Vorraber (Orgs.). Estudos Culturais \& Educação: contingências, articulações, aventuras, dispersões. Canoas/RS: ULBRA, 2015. (243-256).

SILVA, Tomaz Tadeu da; HALL, Stuart; WOODWARD, Kathryn. Identidade e diferença: a perspectiva dos estudos culturais. 7 ed. Petrópolis, RJ: Vozes, 2007. 
TAKARA, Samilo. Uma pedagogia bicha: homofobia, jornalismo e educação. Tese (Doutorado em Educação). Programa de Pós-Graduação em Educação da Universidade Estadual de Maringá (UEM). Maringá, 2017. Disponível em: http://www.ppe.uem.br/teses/2017/2017\%20-\%20Samilo\%20Takara.pdf. Acesso em: 29 jun. 2019.

VIDARTE, Paco. Ética bixa: proclamações libertárias para uma militância LGBTQ. Trad. Maria Selenir Nunes dos Santos. São Paulo: n-1 edições, 2019.

WITTIG, Monique. O pensamento heterossexual. O pensamento hétero. 1980. Disponível em: $<$ http://www.mulheresrebeldes.org/>. Acesso em: 20/01/2018.

\section{SOBRE OS AUTORES:}

\section{Delton Aparecido Felipe}

Professor do Departamento de História e do Mestrado Profissional em Ensino de História da Universidade Estadual de Maringá - Paraná. Pós-Doutor em História e Doutor em Educação pela Universidade Estadual de Maringá (UEM/PR). Pesquisador do Núcleo de Estudos Interdisciplinares Afro-Brasileiros da Universidade Estadual de Maringá - Paraná (UEM/PR). E-mail: ddelton@gmail.com.br

D http://orcid.org/0000-0003-3637-0401

\section{Samilo Takara}

Professor do Magistério Superior no Departamento de Educação da Fundação Universidade Federal de Rondônia, Campus Rolim de Moura/RO. Pós-doutor em Comunicação pela Universidade Estadual de Londrina (UEL/PR). Doutor e mestre em Educação pela Universidade Estadual de Maringá (UEM/PR). Graduado em Comunicação Social Jornalismo pela Universidade Estadual do Centro-Oeste/PR (Unicentro/PR). Líder do Grupo de Estudos e Pesquisas em Estudos Culturais e Educação Contemporânea (GEPECEC/UNIR). E-mail:samilo@unir.br

iD http://orcid.org/0000-0002-8775-6278 